GILBER'T', N. C., DEY, F. L., and RALL, J. E. (1946), f.A.M.A.,

GOLDNER, M. G., and LEVY, J. H. (1947), Gastroenterology, 8,

G88.

HARRINGTON, S. W. (1943), Am. $¥$. Roentgenol., 49, 185.

HARRINGTON, S. W. (I945), Ann. Surg., 122, 546.

JANKELSON, I. R., and MOREIN, S. (I940), Rev. Gastroenterol., I. 134 .

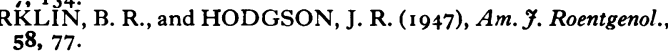

MENDELSON, E. A. (1946), Radiology, 46, 502.

MORRISON, L. G. (1925), F.A.M.A., 84, 161 .

MURPHY, W. P., and HAY, W. E. (1943), Arch. Int. Med., 72, 58.

NAZUM, F. R. (1947), Am. Heart f., 33, 724.
POLLEY, H. F. (1941), F.A.M.A., I16, 821 .

RADLOFF, F. F., and KING, R. L.'(1947), Gastroenterology, 9,

RAU, L. (1949), Proc. Roy. Soc. Med., 42, 864.

RENNIE, J. B., LAND, F. T., and SCOTT PARK, S. D. (1949), Brit. Med. F., 2, 1443.

RITCHEY, J. O., and WINSAUER, H. J. (1947), Am. F. Med. Sc, 214, 476.

RITVO, M. (1930), F.A.M.A., 94, 15.

SAHLER, O. D., and HAMP̈TOM, A. O. (1943), Am. F. Roentgenol., 49, 433 .

SCHWARTZ, S. O., and BLUMENTHAL. S. A. (1949), Am. $\mathcal{F}$ Med., 7, 501 .

SMITHERS, W. D. (1945), Brit. F. Radiol., 18, 199.

TRUEMAN, K. R. (1947), Canad. Med. Ass. F., 56, 149

WEINTRAUB, S., and TRUGGLE, A. (194I), Radiology, 36, 297.

\title{
SYPHILIS OF THE ORAL CAVITY*
}

\author{
$B y$ V. E. Lloyd; M.B., B.S. \\ Dirscior of Department for Venereal Diseases, Guy's Hospital, London
}

The structures of the oral cavity may be affected with syphilis in any of the various stages of that discase. No decade of life is immune, from infancy to senility. A study of the characters of the various lesions and of their course provides an epitome of the habitual behaviour of this exquisitely chronic infection. From various observations upon the lesions of the mouth, tongue and throat we can learn much of the natural history of the disease.

\section{Primary Infection in the Oral Cavity Chancre of the Lip}

It is by no means rare for infection with syphilis to occur in the lip, a chancre in this situation being the most frequent of all the primary lesions which occur in extra-genital locations. It may be seen in the adult or in the child, and upon the upper or lower lip. The chancre is usually an isolated ulcer, situated on the free edge of the lip, presenting the familiar features of a genital chancre, such as indolence, painlessness and slow growth with increasing induration. Because of exposure to the air, the formation of a firm dry crust is more frequently seen than in a genital chancre. Adenitis of the regional lymphatic glands-sub-mental or submaxillary-is well marked. Occasionally the glandular swelling is especially large, densely hard and fixed; simulation of an epithelioma of the lip may then be very close, but the age of the patient, the lack of pain and the absence of a pearly, rolled edge to the ulcer are helpful distinguishing features.

A secondary syphilitic rash is often present in these cases because the lesion has usually been regarded as trivial for some weeks before medical

* Based on a lecture delivered at the Royal College of Surgeons, under the auspices of the Institute of Urology, February 1950. advice is sought. $S$. pallida can be found, by dark ground microscopy, in the exudate from the lesion as readily as from a genital chancre, but when the lesion has been present for four or five weeks and is regressing the number of spirochaetes present is small and their recognition not easy. For some weeks, when the number of spirochaetes is large, the lesions are highly infectious. Schamberg reports a veritable epidemic of chancre of the lips resulting from a party given for adolescents at which the main recreations were kissing games unfortunately a youth was present who had a chancre of the lip, and of the 12 maidens who attended the party seven subsequently developed a chancre of the lip.

Without appropriate treatment a chancre of the lip may persist for many weeks but, eventually, it will heal and absorb leaving only a minute scar. the glandular swelling, however, regresses much more slowly and may be palpable many weeks after the chancre has vanished.

\section{Chancre of the Tongue}

A chancre elsewhere in the oral cavity is much less frequent than one on the lip. They are occasionally seen on the tongue or the tonsil, and rarely on the gum or in the pharynx. In former times when syphilis was more prevalent and when catheterization of the Eustachian tube with unclean instruments was frequently performed, a chancre of the orifice of the Eustachian tube was a not uncommon event.

A chancre of the tongue is more frequent in men than in women, and in middle-aged or elderly men gives rise to a suspicion of a malignant growth, especially when the sub-maxillary lymphatic glands are enlarged and hard, as they often are. The chancre is usually single and situated on the anterior half of the dorsum of the tongue. It may occur as a smooth circular erosion if seen at 


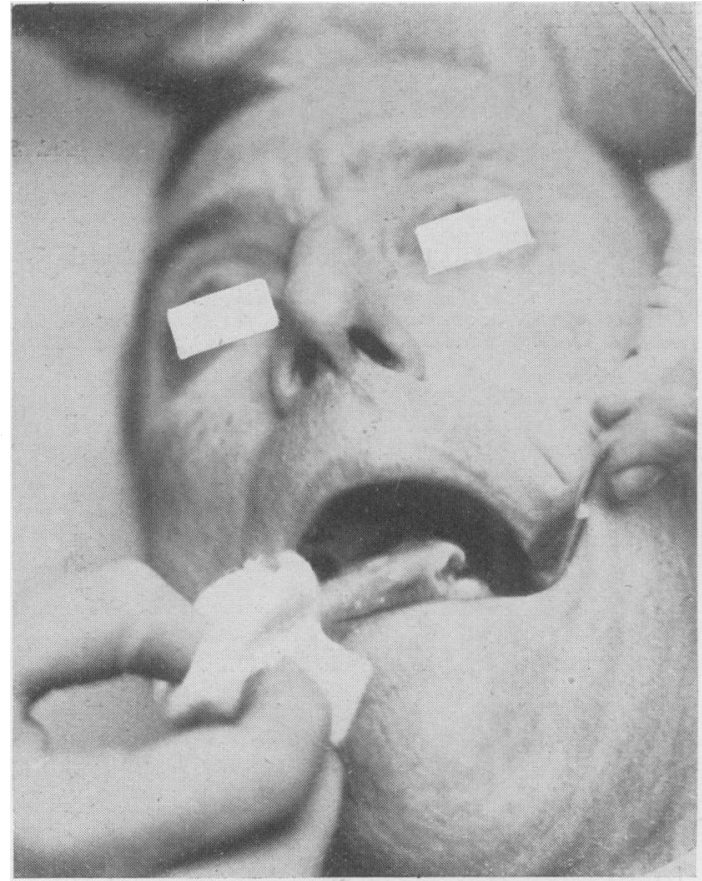

(a)

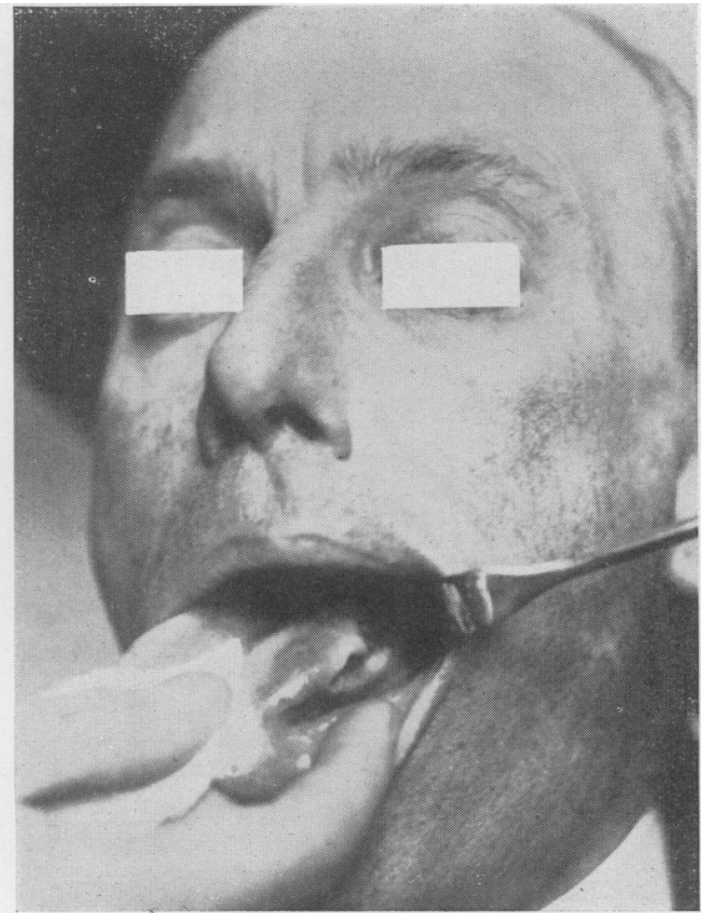

(b)

Fig. I. -9390. Male aged 44. Gummatous ulcer of lateral border of tongue. Noted by patient only I4 days before photography. No history of syphilis. WR ++

Photographic Department, Guy's Hospital

an early stage or, later, as an indurated ulcer of some size. Pain is of slight degree or absent. Occasionally the chancre develops as an indurated mass within the substance of the tongue, with but slight projection and superficial ulceration. The mobility of the tongue may then be impaired and simulation of a carcinoma is particularly close.

The achievement of the correct diagnosis is rarely a simple matter unless the rash of secondary syphilis is present. One of my recent cases illustrates very well some of the difficulties in diagnosis and management which may be encountered.

A man, aged 48 , complained of a sore on the dorsum of the tongue which had increased in size and had become hard and slightly painful over a period of two weeks. His tongue presented an oval ulcer near the lateral border about an inch from the tip. It was about the size of a sixpenny piece, with a raised rounded margin and contained a central grey slough. There was an underlying hard lump in the tongue about the size of a marble. One enlarged gland, hard and discrete but not tender, was found in the superior cervical group.

The Wassermann reaction and the Kahn test were negative. Two attempts to find S. pallida by dark-ground microscopy were made, but without success. The ulcer made no response to treat- ment with potassium iodide, and two weeks later was excised, the incision healing rapidly. Sections were reported as being suggestive of a degenerating fibrosarcoma. The man disappeared for nearly three months and at the end of that period was found to have well-marked extensive secondary syphilis and thoroughly positive serological tests.

Almost certainly this lingual ulcer was a chancre; there was no sign of a chancre elsewhere. The man has been under observation for seven years after antisyphilitc treatment and his tongue has remained normal.

\section{Chancre of the Tonsil}

A chancre of the tonsil is always unilateral and causes considerable swelling of the tonsil, which becomes dusky red in colour and of a firm consistency. There may be superficial ulceration with few symptoms, or a deep ulcer causing pain and dysphagia. A malignant growth or Vincent's angina may be simulated. S. pallida can be found on dark-ground microscopy of the tonsillar exudate, but there may be some confusion owing to the presence of $S$. dentium which is so similar in appearance. As with most chancres, the Wassermann reaction does not become positive until several weeks have elapsed.

The true cause of the tonsillar swelling is often unsuspected for a considerable period. In one of 


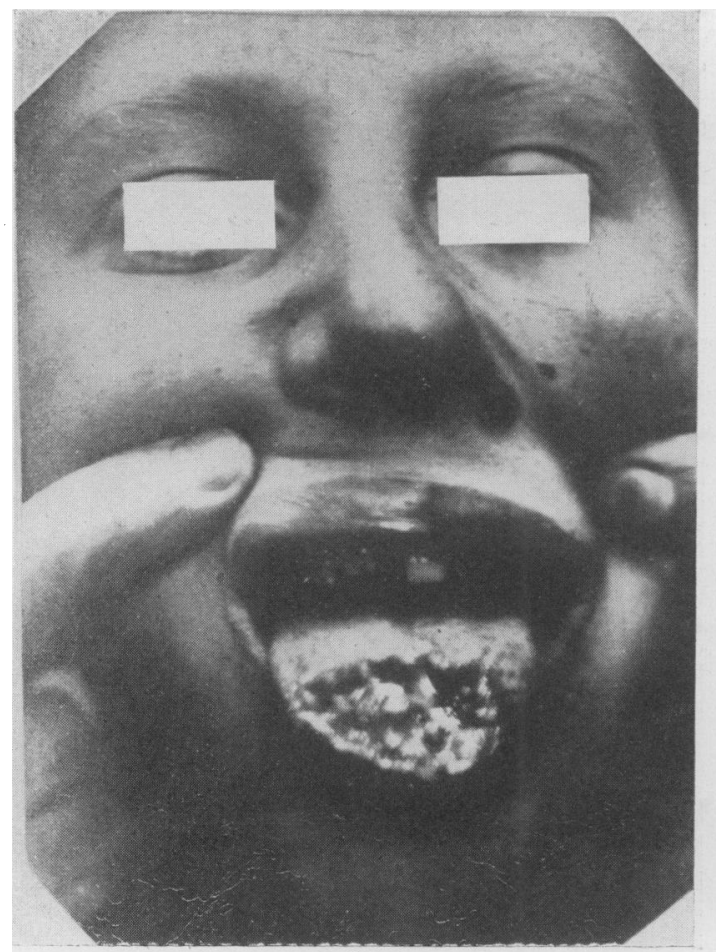

(a)

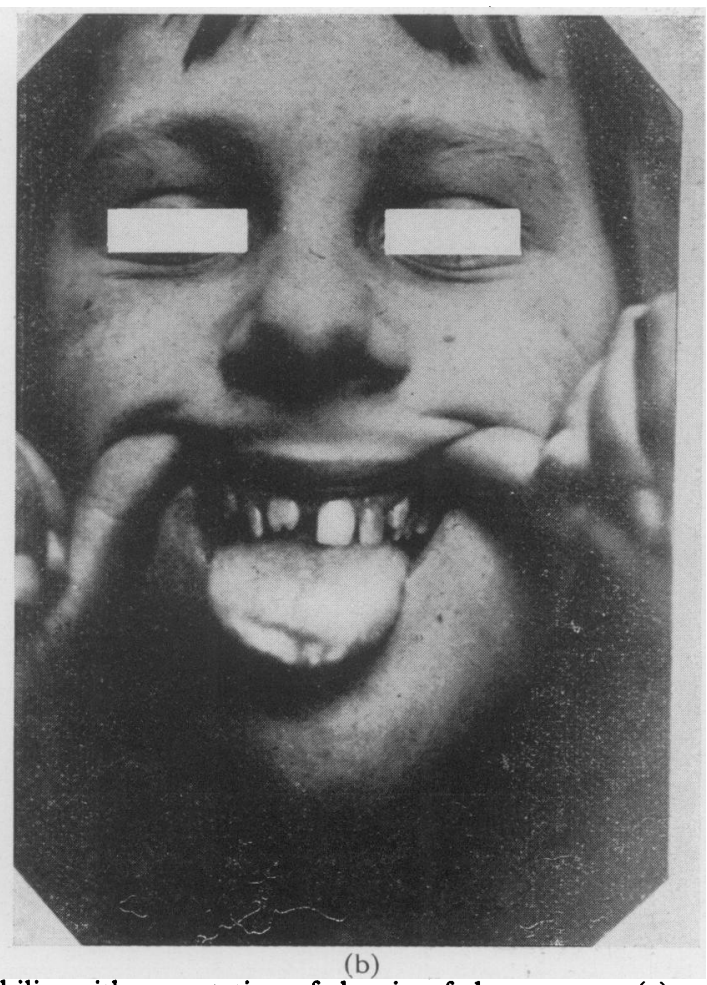

(b)

Fig. 2.-Gummatous ulcer of tongue in congenital syphilis, with amputation of the tip of the tongue. (a) Extensive superficial ulceration of the tip of the tongue of an I I-year-old girl. The ulcer was not tender and tongue movements were free. History of soreness of the tongue for a few weeks only. WR ++ . (b) The tongue ten weeks later after treatment with potassium iodide and weekly N.A.B. injections. (Reproduced by permission of the Hon. Editor of "The British fournal of Venereal Diseases,' and of the publishers, Messrs. Butterworth E' Co. (Publishers) Ltd.)

my four cases the tonsil and surrounding swelling had been incised, as a quinsy, on two separate occasions before the onset of secondary syphilitic manifestations betrayed the true nature of the disease. I have seen a considerable number of patients with secondary syphilis in whom no genital chancre could be found, but by whom a history of a recent prelonged and troublesome tonsillitis was given. A chancre of the tonsil is rarely diagnosed, but I suspect that it is much more common than is generally believed. In one of the cases of secondary syphilis referred to, a dusky-red swollen tonsil was still present and the glands below the angle of the jaw on the same side were much enlarged but not tender. I had little doubt that the tonsillar swelling was due to a recently healed chancre.

\section{Lesions in the Oral Cavity in the Secondary Stage}

Lesions of the mucosa of the oral cavity in the florid secondary stage of syphilis are very frequent, and no doubt most doctors are familiar with their appearance. Similar lesions are seen in young infants suffering from congenital syphilis.

The syphilides in this situation exhibit very clearly the fundamental characters of the lesions of the secondary stage of the disease. These distinctive qualities are their richness in spirochaetes, their multiplicity and symmetry, their transient duration, their lack of destructive tendency and their capacity for healing without scar formation. These oral lesions may appear before, during or after the cutaneous lesions of the secondary stage. Therefore they may be seen in the absence of the syphilitic eruption, a fact which adds to the difficulty of diagnosis. However, signs of an active or recently-healed genital or extra-genital chancre may still be present and a careful search for such a lesion should always be made.

The lesions of the mucosa in the secondary stage are of several varieties. Among the earliest is a small red papule to be seen on the soft palate surrounded by an area of bright erythema. More frequent, in fact very common, are the irregular superficial erosions on the soft palate, lips, fauces and sides or tip of the tongue. These are usually multiple and symmetrical and, at first, present a pearly-grey centre of macerating epithelium, at which stage they are termed 'mucous patches.' Later, when the macerated epithelium has been worn away a superficial erosion is exposed which is 


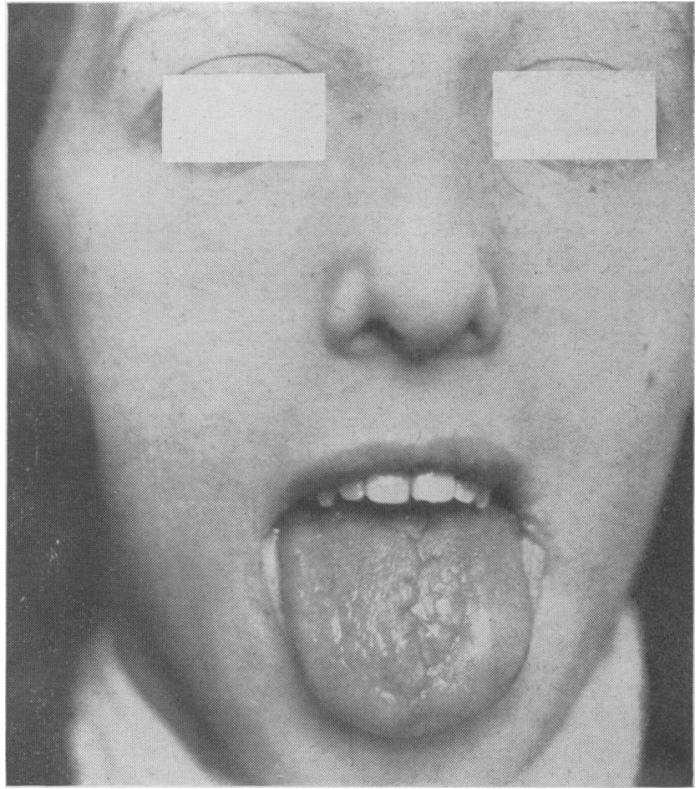

FIG. 3.- ${ }_{506}$ F. Girl aged I 5. WR ++ . Indefinite history of soreness of tongue and inability to eat solids for some years. Crooked linear fissure in centre of dorsum of tongue. Some lobulation at sides of fissure. Slight leucoplakic changes of the lobules. Could eat well eight days after injection of 0.3 ??. N.A.B.

Photographic Department, Guy's Hospital

soft to the touch and is painless. 'The patient is often unaware of the presence of such lesions. These syphilides are usually of brief duration and heal without scar formation.

Not infrequently, especially on the fauces or palate, they increase in area (but not in depth) and coalesce to form extensive, serpiginous areas which have received the very apt name of ' snail track ulcers.' On the fauces or tonsil they may develop occasionally into ulcers of considerable depth, to which secondary bacterial infection is soon added. Sloughs are formed and separate slowly, so that healing is delayed. In some areas, for example on the dorsum of the tongue or at the angle of the mouth, the lesions may become hypertrophic and form elevated papules known as condylomata; they are similar in character to anal condylomata.

Similar lesions are seen on the mucosa of the oral cavity in the congenital syphilitic infant. They occur at or about the same time as the wellknown snuffles and eczema oris syphiliticum. Curiously enough, the adult with secondary syphilis rarely has lesions in the nasal cavity, although this region is by no means immune in the tertiary stage of the disease.

All these lesions of the secondary stage are rich in spirochaetes and are highly infectious. The well-known epidemics of syphilis among glass

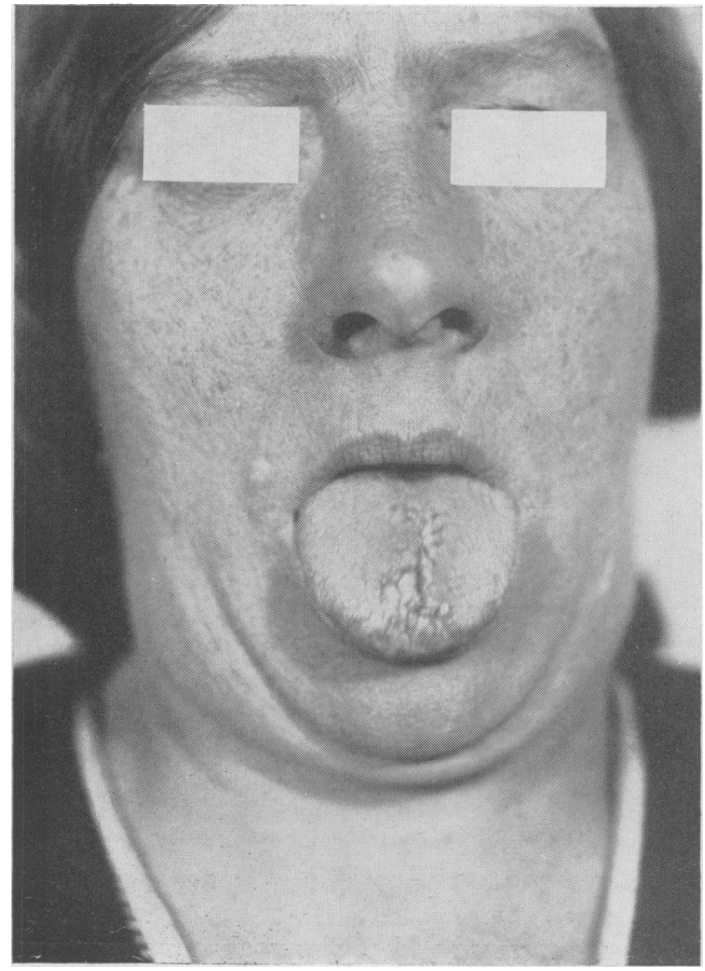

FIg. 4.-6927 F. Aged 48. Parenchymatous glossitis. Central fissure with adjacent lobulation. Slight leucoplakic changes of surface lobules. History of soreness of tongue for 16 months.

Photographic Department, Guy's Hospital

blowers were almost certainly due to a workman having lesions of this type.

The oral cavity may be unaffected by syphilis during the secondary stage and yet suffer later, particularly between the second and fifth year of the infection. These delayed lesions exhibit some of the characters of the tertiary stage, such as greater depth of ulceration, chronicity and slower response to treatment. Such lesions are known as 'precocious tertiaries' because they anticipate the later tertiary period by many years. These lesions sometimes show a considerable resistance to treatment or recur soon after an initial response to treatment.

A good example of this type of refractory ulceration occurred in a man aged 32 years, whom I first saw in 1939 a few months after irregular treatment for a chancre had been given elsewhere over a period of four years. He presented an extensive gummatous infiltration with some scattered ulcers of the posterior wall of the pharynx extending from its upper limit to the level of the cricoid. After eight injections of neoarsphenamine and of a bismuth compound, together with potassium iodide, the ulceration was almost healed but there was still some infiltration of the naso- 


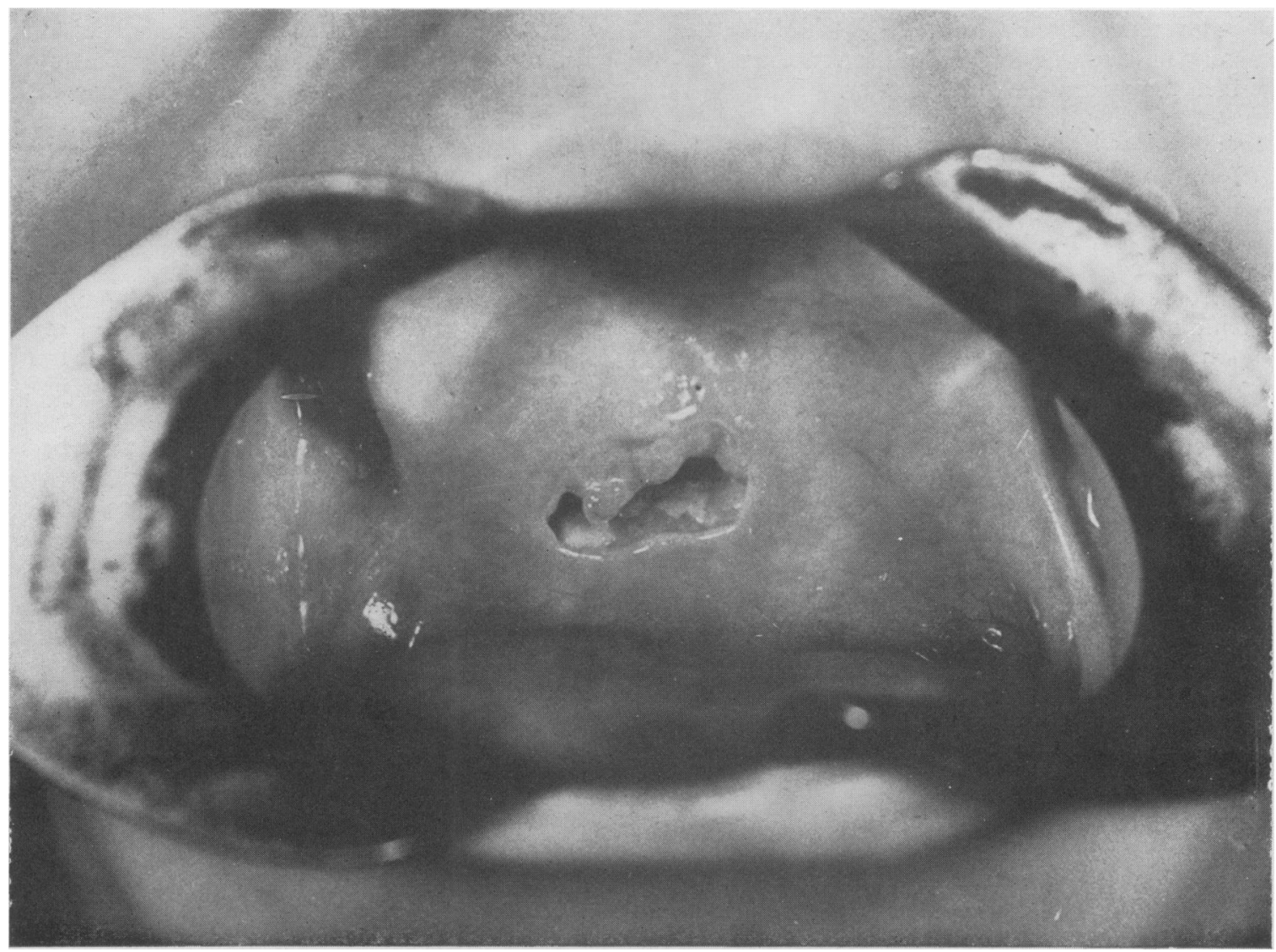

FIg. 5.-Tertiary ulcer of palate. Photographed immediately after removal of the slough. Perforation into nasal cavity. Woman aged 40 . No history of syphilitic infection.

Photographic Department, Guy's Hospital

pharyngeal mucosa. The posterior pillars of the fauces were adherent to the pharyngeal wall. The airway through the nasopharynx was much restricted. A second course of neoarsphenamine and bismuth was given but a week after reaching a total of $5.8 \mathrm{gm}$. of neoarsphenamine and of I I injections of a bismuth preparation, the symptoms returned and the pharynx showed thickened inflamed areas with overlying grey membrane. In spite of continuing the injections an ulcer, $I$ in. in diameter, formed in the posterior pharyngeal wall. This ulcer eventually healed with a continuation of the treatmert, but within three weeks of ceasing treatment it recurred. The patient then disappeared for a period of eight months, at the end of which he had a large ulcer of the pharynx extending forward to involve the postes ior pillars of the fauces.

At this stage, although the Wassermann reaction was repeatedly positive, a tuberculous origin of the ulceration was considered, but appropriate clinical and $\mathrm{X}$-ray examinations showed no supporting evidence. The ulceration eventu- ally healed firmly but with extensive and deforming cicatricial tissue in the pharynx and nasopharynx. By that time I had treated him with a few lapses for nearly three years.

Resistant lesions, although rare, are well known. They appear to be less common in the mucous membranes than in the skin and in most of the reported cases of resistant lesions in the oral cavity they have been situated in the pharynx.

\section{The Tongue in the Tertiary Stage of Syphilis}

Leucoplakia of the tongue is frequently seen in the tertiary stage, chiefly in men; it is much less common in women and is quite a rarity in children with congenital syphilis. Various factors play a part in the production of leucoplakia, e.g. tobacco, alcohol, spices, dental sepsis and syphilis. The condition, however, is not essentially syphilitic in origin.

The true syphilitic affections of the tongue in the tertiary stage are described as being of two main varieties-superficial sclerosing glossitis and deep parenchymatous glossitis. These divisions 
are convenient for the purpose of classification, but there is no sharp dividing line between them and, in fact, they may be found together.

\section{Superficial Sclerosing Glossitis}

In this variety there is a widespread gummatous infiltration of the sub-epithelial tissues of the tongue which gradually involutes and contracts. In appearance the dorsum and sides of the tongue show dark-red areas which are smooth and shiny from atrophy of the papillae. Later, as the condition progresses, the mucosa becomes wi inkled and divided into numerous plaques or lobules. When widely affected the tongue has been termed the 'cobblestone tongue,' a name which fits the picture remarkably well. The surface of the plaques may show leucoplakic changes and fissures may appear in between. The patient rarely complains of any pain until fissures are present. Most of the tongues affected with this variety of glossitis show leucoplakic changes. A long experience of attempts to improve this condition has confirmed the general opinion that leucoplakia itself is relatively unresponsive to antisyphilitic treatment although fissures and ulcers may respond favourably.

There is one important aspect of the results of anti-syphilitic treatment for this condition which I have rot seen mentioned, and that is its effect upon the ultimate development of carcinoma of the tongue. I have yet to see the subsequent development of carcinoma in any of my cases of syphilitic glossitis when thorough anti-syphilitic treatment has been given for that condition. Treatment for any dental sepsis was also given at the same time and no doubt this may have had an important effect.

\section{Deep Parenchymatous glossitis}

Another well known but rare variety of late syphilis of the tongue is that of parenchymatous glossitis, in which the gummatous infiltrations may be widespread throughout the tongue. I have records of 18 cases. In contrast to leucoplakia the two sexes appear to be affected with equal frequency-seven men, nine women and two children, both girls. In the early stage the tongue is enlarged, bright red and tender, but later, with ensuing fibrosis, it pales and shrinks. The contraction is ir regular and the tongue may be distorted by large firm nodules, reminiscent of those seen in a syphilitic liver. Sometimes the nodules are situated deep in the substance of the tongue and unite to form a firm, smooth, painless tumour which, in time, projects on the surface of the tongue usually on the dorsum near the mid-line (five in lateral border in my 18 cases). These deep gummas are slow to break down and the lump may expand slowly for weeks or months. But, eventually, the gumma softens and perforates on the dorsal or lateral aspect of the tongue and then rapidly forms a sloughing ulcer of considerable depth. Until the gumma commences to perforate there may be no pain or tenderness. In contrast to a carcinomatous ulcer the movements of the tongue are unimpaired and unless the gummatous ulcer becomes heavily infected with pyogenic organisms the cervical glands do not enlarge.

In cases of chronic ulcer of the tongue, even when the infection of syphilis is recognized from blood tests or the presence of syphilitic lesions elsewhere in the patient, there may still be much doubt as to the nature of the ulcer. It has been customary for many years to use the rapid healing action of the iodides or of neoarsphenamine as a therapeutic test. Penicillin will doubtless be used in a similar manner, and a recent experience in this respect is not without interest.

This was in the case of a man aged 52 years who had two lingual ulcers of about six weeks' duration. One of the ulcers was small and superficial and was situated on the tip of the tongue. The other was a large deep ulcer, tender and indurated, situated on the left lateral border of the tongue. No enlarged lymphatic glands could be detected. The mobility of the tongue was ex cellent. The Wassermann test was strongly? positive.

The diagnosis was in doubt because the remainder of the tongue showed no leucoplakia or signs of syphilitic glossitis, and the ulcers contained no wash-leather slough. Whilst the patient was awaiting admission to hospital for a biopsy I treated him with $3 \mathrm{~m}$.u. penicillin in eight days. By the eighth day the ulcers were smaller, cleanc $r$ and less painful. Nevertheless biopsy revealed carcinomatous changes in both ulcers. As a result of this experience I feel that penicillin should not be used in a differential therapeutic test for syphilis in lingual ulcers of uncertain origin.

Gummatous ulceration in the floor of the mouth or on the under surface of the tongue appears to be rare; I have not seen an example of this nature. Gummatous infiltration commencing in the mucosa of the cheek is rare, although an extension into the cheek from a tertiary cutaneous syphilide is not uncommon. I can recollect seeing only one example in this location, in which a localized gummatous swelling of characteristic type, and of about the diameter of a penny, was situated in the mucosa of the cheek in apposition with the right upper molar teeth of an elderly man. The swelling ulcerated in a few weeks and, after the separation of a deep slough, healed promptly after treatment with iodides and neoarsphenamine. Subsequent scarring and deformity was very slight. 


\section{Gummatous Inflammation of the Palate, Fauces and Pharynx}

On the recrudescence of syphilis, after the interval of the torpid latent stage in both acquired and congenital syphilis, the mucosa of the palate, fauces, tonsil and pharynx is frequently affected by gummatous infiltration. In these regions we see the destructive tendency of gummatous inflammation at its worst. Examples of gross ulceration are by no means rare, even at the present day. This gummatous infiltration may appear in either sex and at almost any age. In my series of 100 cases the ages ranged from four to 70 .

Tertiary syphilis or late congenital syphilis in these regions may appear as a diffuse indolent infiltration of the mucosa or as a flattened tumour of slow growth. The former-gummatous infiltration--presents as a thickened congested area of the mucosa, dull red in colour, relatively painless and firm to the touch. In some patients there is slight local discomfort which may have been present for weeks or months. Eventually ulceration takes place and may spread widely creating an indolent ulcer, serpiginous in outline, which may heal in one area whilst advancing in another. The condition, even then, may exist without prominent symptoms.

Less often tertiary syphilis presents as a small localized tumour-the gumma-which forms a smooth rounded mass of a dull red colour. Local pain may be absent and tenderness may be only of slight degree. The small tumour, which at first is firm, slowly softens from central necrosis and on the surface a small necrotic area appears which rapidly develops into a deep, punched-out ulcer with a central adherent slough of the appearance of wet wash-leather. The amount of tissue destruction is invariably greater than at first is apparent and cannot be fully appreciated until the slough has separated and been removed.

\section{Palate and Fauces}

Gummatous infiltration of the palate usually occurs in the mid-line of the hard or soft palate and is particularly prone to rapid and deep ulceration. In many cases this leads to a small perforation of the palate communicating with the nasal cavity or to even more extensive destruction of the palate or fauces. Among 81 of my cases of ulceration of the palate in the late stage of syphilis there were one or more perforations into the nasal cavity in 28. In some instances the perforation was a tiny slit or a small round hole which gave rise to little disability. But in others the opening was large enough to permit constant regurgitation of fluids into the nose on swallowing. When ulceration appears in the mucosa attached to the hard palate there is almost always some local underlying periostitis, and bony necrosis with perforation is not uncommon. Sometimes the destruction is so widespread that the greater part of the hard and soft palate is destroyed leaving a wide cleft through which the turbinate bones can easily be seen. The patient's voice is grossly altered in tone when a large perforation is present.

Gummatous infiltration may also affect the tonsils and pillars of the fauces in a similar manner, but less frequently than in the palate. The same tendency to gross destruction of tissue with subsequent deformity on healing is seen in these structures. The uvula often disappears completely. A perforation in the upper part of the anterior pillar of the fauces is sometimes seen; it is usually unilateral, slit-like in appearance and set in the long axis of the anterior pillar. An isolated gumma of the tonsil, in the absence of involvement of the palate or pharynx, appears to be rare (there were four examples in my series of roo cases) and gives rise to considerable difficulty in diagnosis. In contradistinction to an ulcerated malignant growth there is less pain and less tendency to bleed in a syphilitic ulcer; and involvement of the cervical glands is not common. But in these cases as in many others when there is any doubt about the nature of the ulcer on clinical grounds it is wise to perform a biopsy and to avoid being too impressed by a positive Wassermann test.

I have learnt by bitter experience to regard these late gummatous affections of the palate and fauces as therapeutic urgencies. Perforation or extensive sloughing of the soft palate, uvula and fauces may take place very rapidly. Treatment, at the very least with potassium iodide, should- be commenced as soon as a syphilitic origin of the ulceration is suspected. In the past I have greatly regretted delaying treatment until the report of a Wassermann test has arrived, for in the few days' interval that elapsed I have known ulceration to progress rapidly and to cause destruction of tissues that might have been avoided by prompt treatment.

TABLE I

Distribution of Gummatous Ulcers in 100 Cases of Syphilis of the Oral Cavity (Excluding Tongue)

\begin{tabular}{|c|c|c|c|}
\hline & Palate & Tonsil & Pharynx \\
\hline $\begin{array}{c}\text { Acquired: } \\
\text { Men } \\
\text { Women }\end{array}$ & $\begin{array}{l}45 \\
19\end{array}$ & $\begin{array}{r}\text { I I } \\
4\end{array}$ & $\begin{array}{r}15 \\
9\end{array}$ \\
\hline $\begin{array}{c}\text { Congenital : } \\
\text { Male } \\
\text { Female }\end{array}$ & $\begin{array}{r}7 \\
10\end{array}$ & $\begin{array}{l}0 \\
\mathbf{I}\end{array}$ & $\begin{array}{l}\text { I } \\
4 y\end{array}$ \\
\hline Total number of lesions & 81 & 16 & 29 \\
\hline
\end{tabular}




\section{Pharynx}

In the pharynx gummatous infiltration or ulceration in the late stage of congenital or acquired syphilis may occur in the lateral or posterior walls of the nasopharynx and oropharynx, but it is less frequent than similar involvement of the palate or fauces-29 instance in my 100 cases of gummatous involvement of the oral cavity. In the nasopharynx the lesion is often invisible except to rhinoscopy, and the nasopharyngeal isthmus may be tlocked up by the swelling. In general, the gummatous inflammation is slowly progressive and after remissions and subsequent recrudescences over some years may involve extensive areas of the lateral and posterior walls of the pharynx.

The symptoms vary with the extent of the disease. When the lesion is small there may be slight dysphagia and excess of mucus only. In more extensive infiltrations or ulceration dysphagia is a prominent complaint and the pain may radiate to the ear. Deafness from blocking of the Eustachian tube is not uncommon and otitis may ensue. The difficulty in swallowing may be considerable and in severe cases fluids only can be swallowed. A foul discharge may emanate from the ulcers, particularly from those situated in the nasopharynx.

The ulcerated areas heal in time and are replaced by dense scar tissue. Additional ulcers appear and slowly heal. Finally large sections of the pharyngeal walls are replaced by extensive irregular cicatricial areas or bands with pits or chronic ulcers in between. The thickened and scarred pharyngeal tissues tend to become adherent to the anterior aspect of the cervical vertebrae, which may be the seat of syphilitic osteitis and necrosis. The mobility of the pharynx during deglutition is much impaired and this, together with the accompanying narrowing and rigidity of the walls of the nasopharynx, constitutes a serious disability. There may be constant regurgitation of fluids into the nose from inability to close the nasophas ynx during swallowing; further, nasal respiration may be much restricted or prevented.

Gummatous infiltration of the fauces often occurs at the same time as that in the nasopharynx. There is a tendency for the swollen ulcerated areas to become adherent to similar areas in the nasopharynx. Later, on healing, the nasopharyngeal isthmus is reduced by contraction into a small channel surrounded by dense scar tissue-a veritable stricture of the nasopharynx. There is then much impairment of the functions of speech, respiration and deglutition. In my series of 29 cases of severe tertiary ulceration of the pharynx there are five instances of such gross deformity.

It is curious that among the roo cases of ulceration in the palate, fauces or pharynx there was no instance of simultaneous gummatous disease of the tongue.

\section{H. K. LEWIS \& Co. Ltd Medical Publishers and Booksellers}

Catalogues on request State interests 136 GOWER STREET LONDON, W.C.1 (Adjoining University College and Hospital)

Teleohone: EUSton 4282 (7 lines) Telegroms : Publicavie, Westcent, London Business hours: 9 a.m. to 5 p.m. Saturdays: 1 p.m.

\section{Medical Lending Library}

ANNUAL SUBSCRIPTION frOm TWENTY-FIVE SHILINGS

For the CONVENIENCE of POST-GRADUATE STUDENTS SHORT PERIOD SUBSCRIPTIONS ARE ARRANGED - for 3 or 6 months Detailed Prospectus on opplication

The Library Catalogue revised to December, 1949, containing classified index of authors and subjects. Ready this month.

To subscribers 17/6 net; To non-subscribers 35/- net. Postage 1/Bi-Monthly List of New Books and New Editions sent post free on request

NEW BOOKS ADDED IMMEDIATELY UPON PUBLICATION 